\title{
Association of G72/G30 polymorphisms with early-onset and male schizophrenia
}

\author{
Weihua Yue ${ }^{\mathrm{a}, *}$, Zhonghua Liu ${ }^{\mathrm{a},{ }^{*}}$, Guolian Kang, ${ }^{\mathrm{b}, \mathrm{c}}$, Jun Yan ${ }^{\mathrm{a}}$, Fulei Tang ${ }^{\mathrm{a}}$, Yan Ruan ${ }^{\mathrm{a}}$, Jifeng Zhang ${ }^{\mathrm{b}}$ \\ and Dai Zhang ${ }^{\mathrm{a}}$
}

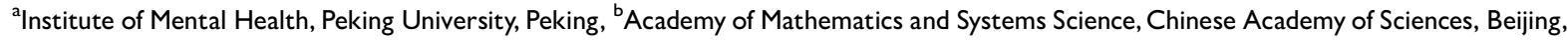
China and ${ }^{\mathrm{C}}$ Department of Statistics and Probability, Michigan State University, East Lansing, Michigan, USA

Correspondence and requests for reprints to Professor/Dr Dai Zhang, MD, PhD, Institute of Mental Health, Peking University, 5I, Hua Yuan Bei Road, Peking, Beijing 100083, China

Tel: + 8610 82801937; fax: + 8610 62078246; e-mail: daizhang@bjmu.edu.cn
\end{abstract}

*These authors contributed equally to this work.

There are no conflicts of interest.

Sponsorship:This work was supported by Grants 30530290, 30400149 from the National Natural Science Foundation of China and Grant 2002BA7IIA07-06 from the National Key Project.

Received 7 August 2006; accepted 25 August 2006

To explore the effect of $G 72 / G 30$ polymorphisms on the clinical manifestations of schizophrenia, especially on the age at onset and sex of patients, we examined three single nucleotide polymorphisms in 216 schizophrenic patients and 321 healthy controls. Significant associations of schizophrenia with the $A$ allele of rs947267 ( $P=0.012)$ and haplotype A-A-G (rs2391191-rs947267rs778294) $(P=0.008)$ were found in early-onset schizophrenic patients. So did the same allele $(P=0.034)$ and haplotype $(P=0.009)$ as mentioned above in male patients. These findings suggest that the G72/G30 gene may modulate the age at onset and there might be a potential interaction between this locus and sex in the pathogenesis of schizophrenia. NeuroReport 17:1899-1902 (c) 2006 Lippincott Williams \& Wilkins.

Keywords: age at onset, association study, G72/G30, polymorphism, schizophrenia

\section{Introduction}

Schizophrenia is a major psychiatric disorder that affects almost $1 \%$ of the world's population and accounts for about $2.5 \%$ of healthcare costs [1]. Symptoms usually begin in late adolescence or early adulthood. Involvement of neurodevelopmental mechanism, especially glutamatergic transmission via $N$-methyl-D-aspartate receptors and synaptic plasticity in schizophrenia, has been recently suggested, on the basis of several lines of evidence [2]. Linkage analyses on diverse samples have provided accumulating evidence that chromosome 13q32-q33 may be involved in susceptibility to schizophrenia. A meta-analysis of genomewide linkage studies further identified 13q32-q33 as significantly linked to schizophrenia [3].

Chumakov et al. [4] first reported that genetic variations near G72 (MIN 607408) and G30 (MIN 607415) locus on 13 q34 were associated with schizophrenia in FrenchCanadian and Russian cohorts. G72 and G30 overlap on complementary chromosomal strands and are therefore transcribed in opposite directions. By yeast two-hybrid experiments, Chumakov et al. [4] also identified that the G72 protein interacts with the enzyme D-amino acid oxidase (MIN 124050), which regulates glutamatergic signaling through an $N$-methyl-D-aspartate receptor pathway. Gene expression analysis of G72 and G30 exhibited correlations between expression levels of the G72 and G30 genes, as well as a tendency toward overexpression of G72 mRNA in schizophrenic post-mortem dorsolateral prefrontal cortex of 44 schizophrenic patients compared with 44 control participants [5].

Hattori et al. [6] suggested that a susceptibility variant for both bipolar illness and schizophrenia exists in the vicinity of the G72/G30 gene in two series of pedigrees. Findings from several subsequent studies tend to advance a role for G72/G30 in the overall risk for schizophrenia and bipolar disorder from various populations, including a metaanalysis study and a research based on a sample of childonset schizophrenia [7-14]. The majority of replication studies have, however, been inconsistent with respect to the associated alleles or haplotypes. Moreover, negative associations of $G 72 / G 30$ polymorphisms with schizophrenia were also reported $[15,16]$.

Nevertheless, G72/G30 locus may be candidate genes for the pathogenesis of schizophrenia or disease modification. The present investigation is an association study to test the hypothesis that G72/G30 polymorphisms are related to schizophrenia susceptibility and/or age at schizophrenic onset or sex. 


\section{Materials and methods}

Our study sample consisted of 216 patients with schizophrenia (120 men and 96 women; mean age: $30 \pm 10$ years) and 321 healthy controls (184 men and 137 women; mean age: $31 \pm 11$ years) who were group-matched for age, sex and ethnicity. All of the participants were Chinese Han descendants. A part of this sample has been used in our previous study [17]. The age of clinical symptoms onset (1353 years, mean 25.67 years) was retrospectively estimated as the time of emergence of any schizophrenic symptoms according to the International Classification of Diseases-10. The objectives and procedures of the study were explained to all participants and written informed consent was obtained. Research ethics committee approval was obtained from the Ethical Committee of Peking University Health Science Center.

Three single nucleotide polymorphisms (SNPs) (rs2391191, rs947267, r778294) were genotyped either with the polymerase chain reaction (PCR)-based restriction fragment length polymorphism genotyping or with direct DNA sequencing. The construction of $25 \mu \mathrm{l}$ PCR reaction mixture and the condition of PCR amplification were performed to be the same as that reported in our previous study [17], with annealing temperatures of $55-62^{\circ} \mathrm{C}$. Fifteen microliter PCR products were digested completely with $2 \mathrm{U}$ of restriction enzyme (HaeIII for rs947267, BsrI for rs778294) and electrophoresed subsequently on 2-4\% agarose gels stained with ethidium bromide. For rs2391191, the PCR products were sequenced on an ABI PRISM 377-96 DNA Sequencer (Applied Biosystem, Foster City, California, USA).

Deviation of the genotype counts from the HardyWeinberg equilibrium was tested using a $\chi^{2}$ goodness-offit test. The pairwise linkage disequilibrium (LD) analysis was applied to detect the inter-marker relationship, using $D^{\prime}$-value. The case-control association analysis was performed by SHEsis (Bio-X Life Science Research Center, Shanghai, China) a powerful software platform for analyses of LD, haplotype construction and genetic association at polymorphism loci [18]. Results were considered significant at two-tailed $P<0.05$.

\section{Results}

Genotype frequencies of any of SNPs rs2391191, rs947267, rs778294 in case and control groups did not show significant deviations from Hardy-Weinberg equilibrium (data not shown). Neither rs2391191 nor rs778294 revealed significant allelic association in case-control samples. A significant difference in frequency of allele was, however, found in SNP rs947267 $[\mathrm{A}>\mathrm{C}, P=0.006$; odds ratio $(\mathrm{OR})=1.43,95 \%$ confidence interval (CI), 1.11-1.85] between schizophrenic patients and healthy controls (Table 1). With the intermarker LD calculation, the three SNPs were found to be in strong LD $\left(D^{\prime}>0.7\right)$ with each other. Multilocus association analysis showed that haplotype A-A-G constructed by rs2391191, rs947267 and rs778294 was also associated with schizophrenia in the total group $(P=0.003, \mathrm{OR}=1.46,95 \%$ CI, 1.14-1.87) (Table 2).

The results of comparison between early-onset schizophrenic (age at onset $<18$ years) patients and groupmatched controls (age $<18$ years) also revealed a significant association of the A allele of SNP $\operatorname{rs947267~}(P=0.012$, $\mathrm{OR}=1.67,95 \% \mathrm{CI}, 1.13-2.51)$ and haplotype A-A-G $(P=0.008, \mathrm{OR}=1.67,95 \% \mathrm{CI}, 1.13-2.29)$ with schizophrenia. Further analysis stratified by sex showed that the same allele $(P=0.034, \mathrm{OR}=1.45,95 \% \mathrm{CI}, 1.03-2.04)$ and haplotype $(P=0.009$, OR $=1.54,95 \% \mathrm{CI}, 1.11-2.14)$ (Tables 1 and 2) as mentioned above were significantly associated with schizophrenia in male patients compared with male controls, but not in female patients (data not shown). Furthermore, these results, except two haplotypes, still remain significantly associated with schizophrenia, after using the permutation method to obtain empirical $P$ values.

\section{Discussion}

In this study, we reported the association of an SNP (rs947267) and a haplotype located in the G72/G30 gene with schizophrenia, age at onset and sex in a Chinese population. The results revealed that rs947267 and the haplotype constructed by three SNPs might increase the susceptibility of schizophrenia or might be linked with

Table I Allele frequencies of each SNP of G72/G30 genes and the results of comparison between case and control groups

\begin{tabular}{|c|c|c|c|c|c|c|c|}
\hline Group & SNP & Allele & No. patients (freq) ${ }^{\mathrm{a}}$ & No. controls (freq) ${ }^{\mathrm{a}}$ & $\chi^{2}$ & $P$ value $^{\mathrm{b}}$ & $\mathrm{OR}^{\mathrm{c}}(95 \% \mathrm{Cl})$ \\
\hline \multirow[t]{3}{*}{$\begin{array}{l}\text { Total (no. patients: } \\
\text { 216; no. controls: } 32 \mathrm{l} \text { ) }\end{array}$} & MI5 & $\begin{array}{l}A \\
G\end{array}$ & $\begin{array}{l}276(0.64) \\
156(0.36)\end{array}$ & $\begin{array}{l}394(0.61) \\
248(0.39)\end{array}$ & 0.698 & 0.404 & I.II (0.87-I.42) \\
\hline & MI8 & $\begin{array}{l}\mathrm{A} \\
\mathrm{C}\end{array}$ & $\begin{array}{c}299(0.69) \\
133(0.31)\end{array}$ & $\begin{array}{l}392(0.61) \\
250(0.39)\end{array}$ & 7.483 & 0.006 & I.43 (I.II-I.85) \\
\hline & MI9 & $\begin{array}{l}A \\
G\end{array}$ & $\begin{array}{c}43(0.10) \\
389(0.90)\end{array}$ & $\begin{array}{c}74(0.12) \\
560(0.88)\end{array}$ & 0.776 & 0.378 & $1.20(0.79-1.82)$ \\
\hline \multirow[t]{3}{*}{$\begin{array}{l}\text { EOS (no. patients: } \\
88 ; \text { no. controls: }|3| \text { ) }\end{array}$} & MI5 & $\begin{array}{l}A \\
G\end{array}$ & $\begin{array}{l}\text { II3 }(0.64) \\
63(0.36)\end{array}$ & $\begin{array}{l}160(0.61) \\
102(0.39)\end{array}$ & 0.441 & 0.507 & $\mathrm{I} .14(0.77-1.68)$ \\
\hline & MI8 & $\begin{array}{l}\mathrm{A} \\
\mathrm{C}\end{array}$ & $\begin{array}{l}\text { I2I (0.69) } \\
55(0.31)\end{array}$ & $\begin{array}{l}149(0.57) \\
\text { II3 }(0.43)\end{array}$ & 6.284 & 0.012 & $1.67(I .13-2.51)$ \\
\hline & MI9 & $\begin{array}{l}\mathrm{A} \\
\mathrm{G}\end{array}$ & $\begin{array}{c}18(0.10) \\
158(0.90)\end{array}$ & $\begin{array}{c}33(0.13) \\
229(0.88)\end{array}$ & 0.574 & 0.449 & $1.26(0.69-2.29)$ \\
\hline \multirow[t]{3}{*}{$\begin{array}{l}\text { Men (no. patients: } \\
\text { I20; no. controls: } 184 \text { ) }\end{array}$} & MI5 & $\begin{array}{l}A \\
G\end{array}$ & $\begin{array}{l}154(0.64) \\
86(0.36)\end{array}$ & $\begin{array}{l}224(0.61) \\
144(0.39)\end{array}$ & $0.67 \mathrm{I}$ & 0.413 & $1.15(0.82-1.61)$ \\
\hline & MI8 & $\begin{array}{l}\mathrm{A} \\
\mathrm{C}\end{array}$ & $\begin{array}{l}167(0.70) \\
73(0.30)\end{array}$ & $\begin{array}{l}225(0.61) \\
43(0.39)\end{array}$ & 4.520 & 0.034 & $1.45(1.03-2.04)$ \\
\hline & MI9 & $\begin{array}{l}\mathrm{A} \\
\mathrm{G}\end{array}$ & $\begin{array}{l}22(0.09) \\
218(0.91)\end{array}$ & $\begin{array}{c}40(0.11) \\
328(0.89)\end{array}$ & 0.460 & 0.498 & I.21 (0.70-2.10) \\
\hline
\end{tabular}

SNP, single nucleotide polymorphism; OR, odds ratio; $\mathrm{Cl}$, confidence interval; EOS, early-onset schizophrenia; freq, frequency.

${ }^{a}$ The numbers of alleles (allele frequencies are shown in parentheses).

${ }^{\mathrm{b}}$ The values in boldface type are nominally significant $P$ value $(P<0.05)$.

${ }^{c}$ ORs of alleles were calculated for each reference vs. variant allele. MI5-rs239II9I; MI8-rs947267; MI9-rs778294. 
Table 2 Results of haplotype of $G 72 / G 30$ genes distribution and analysis in case and control groups

\begin{tabular}{|c|c|c|c|c|c|c|c|}
\hline Group & Marker & Haplotype & Freq in case $\mathrm{e}^{\mathrm{a}}$ & Freq in control ${ }^{\mathrm{a}}$ & $P$ value $^{\mathrm{b}}$ & Global $P$ value $^{\text {b }}$ (d.f. $)^{c}$ & $\mathrm{OR}(95 \% \mathrm{Cl})^{\mathrm{d}}$ \\
\hline \multirow[t]{4}{*}{ Total (no. patients: 216 ; no. controls: $32 \mathrm{l}$ ) } & MI5-MI8 & A-A & 0.54 & 0.47 & 0.039 & $0.028(3)$ & $1.25(1.01-1.54)$ \\
\hline & MI5-MI9 & $A-G$ & 0.58 & 0.55 & 0.433 & $0.335(3)$ & I.IO (0.87-I.40) \\
\hline & MI8-MI9 & A-G & 0.67 & 0.61 & 0.027 & $0.023(3)$ & $1.33(1.03-1.71)$ \\
\hline & MI5-MI8-MI9 & A-A-G & 0.50 & 0.45 & 0.003 & $0.006(7)$ & 1.46 (1.14-1.87) \\
\hline \multirow{4}{*}{ EOS (no. patients: 88 ; no. controls: |3|) } & MI5-MI8 & A-A & 0.56 & 0.45 & 0.017 & $0.023(3)$ & $1.59(1.09-2.33)$ \\
\hline & MI5-MI9 & $A-G$ & 0.57 & 0.55 & 0.673 & $0.281(3)$ & $1.09(0.73-1.63)$ \\
\hline & MI8-MI9 & $A-G$ & 0.69 & 0.59 & 0.031 & $0.040(3)^{\mathrm{e}}$ & $1.56(1.04-2.34)$ \\
\hline & MI5-MI8-MI9 & $A-A-G$ & 0.53 & 0.40 & 0.008 & $<0.001(7)$ & $1.67(1.13-2.29)$ \\
\hline \multirow[t]{4}{*}{ Men (no. patients: I20; no. controls: 184) } & MI5-MI8 & A-A & 0.55 & 0.45 & 0.017 & $0.024(3)$ & $1.45(1.04-2.02)$ \\
\hline & MI5-MI9 & $A-G$ & 0.59 & 0.56 & 0.543 & $0.281(3)$ & I.II $(0.79-1.55)$ \\
\hline & MI8-MI9 & $A-G$ & 0.67 & 0.58 & 0.039 & $0.042(3)^{\mathrm{e}}$ & $1.42(1.02-1.98)$ \\
\hline & MI5-MI8-MI9 & A-A-G & 0.53 & 0.42 & 0.009 & $<0.001(7)$ & $1.54(1.11-2.14)$ \\
\hline
\end{tabular}

Data of other rare haplotypes $(<\mathrm{I} \%)$ in both case and control groups are not presented.

$\mathrm{OR}$, odds ratio; $\mathrm{Cl}$, confidence interval; $\mathrm{EOS}$, early-onset schizophrenia; freq, frequency.

${ }^{a}$ Haplotype frequencies are shown in cases and controls, respectively.

${ }^{b}$ Global haplotype represents the haplotype using all possible variants. The value in boldface type is a nominally significant $P$ value $(P<0.05)$.

'The d.f. values are shown in parentheses.

${ }^{d}$ ORs of haplotypes were calculated for each haplotype vs. all others.

eThese permutation $P$ values $>0.05$.

the disease locus along with other genetic markers. The negative association results of rs2391191 and rs778294, which were in strong LD with rs947267, may be due to their minor effects compared with the whole effects of haplotypes. The three SNPs in our study, rs2391191, rs947267 and rs778294, were all tested in Chumakov's study (named M15, M18, M19, respectively), in which none of the markers was associated with schizophrenia in either FrenchCanadian or Russian populations [4]. Subsequently, several replication studies have been inconsistent with regard to the association of the above SNPs with schizophrenia or bipolar disorder [5-8,10,12-16]. In a meta-analysis study, DeteraWadleigh and McMahon [11] reported that rs2391191 was associated with schizophrenia, but not with bipolar disorder, and neither rs947267 nor rs778294 was associated with schizophrenia or bipolar disorder. In a recent report, the SNP rs947267 has been found to be associated with schizophrenia in male patients [19].

There might be several explanations about the inconsistent association findings. First, the pathogenic mutations of G72/G30 are not exactly the same across populations. For example, in both European (CEU) and Chinese (CHB) populations, rs2391191, which gives rise to a missense mutation, and the frequencies of major allele is the allele G in European populations (0.658 in CEU, HapMap), in Chinese populations it is the allele A $(0.522, \mathrm{CHB}$, HapMap). Furthermore, Detera-Wadleigh and McMahon [11] reported the difference in LD among polymorphisms between different continental populations. Second, there is a positive association between the above SNPs and schizophrenia in some degree, owing to potential LD between the above polymorphisms and any other functional variants located in or adjacent to the G72/G30 gene. Third, phenotypic heterogeneities, such as sex, age at onset and other clinical markers, may influence the genetic loading of participants' vulnerability to schizophrenia [20]. Stratification by age of onset and sex may serve to identify a more homogeneous patient group, less confounded by potential secondary effects of illness and with a more salient genetic risk [21].

Several implications exist for our findings that G72/G30 polymorphisms are associated with schizophrenia in early-onset and male patients. The neurodevelopmental hypothesis of schizophrenia is based, at least in part, on the presence of premorbid impairments seen in children and adolescents who later develop schizophrenia. Aberrant neurodevelopment may be even more relevant for schizophrenia with early-onset schizophrenic [22]. Epidemiological surveys of schizophrenia have demonstrated that the two genders differ in age at onset, course of illness, clinical symptoms and outcome of disease. Many factors may account for this sex difference. Besides the sex steroid hormones, genetic factors might also be implicated. An apparent excess of sex chromosome aneuploidies (XXY and $X X X)$ has been reported in populations of patients with schizophrenia, and schizophrenic sib-pairs are more often of the same sex than of the opposite sex [23]. Furthermore, there might be an interaction between the gene and sex on the pathogenesis of schizophrenia. The biological function of the above SNPs of G72/G30 still remains unknown and probing into the potential function of polymorphisms might be helpful in exploring their effects on the development of schizophrenia.

\section{Summary}

Our result demonstrated a significant association between G72/G30 polymorphisms and schizophrenia, so did in the early-onset and male patients with schizophrenia. Although more work is needed to explain the differences in alleles and haplotypes across studies, the overall evidence strongly supports association of the G72/G30 locus with schizophrenia. Identification of functional variants will probably require biological as well as additional genetic assays.

\section{Acknowledgements}

We thank all of the patients and families included in this study.

\section{References}

1. Meltzer D. Perspective and the measurement of costs and benefits for cost-effectiveness analysis in schizophrenia. J Clin Psychiatry 1999; 60 (Suppl 3):32-35; discussion 36-37. 
2. Harrison PJ, Weinberger DR. Schizophrenia genes, gene expression, and neuropathology: on the matter of their convergence. Mol Psychiatry 2005; 10:40-68.

3. Badner JA, Gershon ES. Meta-analysis of whole-genome linkage scans of bipolar disorder and schizophrenia. Mol Psychiatry 2002; 7:405-411.

4. Chumakov I, Blumenfeld M, Guerassimenko O, Cavarec L, Palicio M, Abderrahim $\mathrm{H}$, et al. Genetic and physiological data implicating the new human gene G72 and the gene for D-amino acid oxidase in schizophrenia. Proc Natl Acad Sci USA 2002; 99:13675-13680.

5. Korostishevsky M, Kaganovich M, Cholostoy A, Ashkenazi M, Ratner Y, Dahary D, et al. Is the G72/G30 locus associated with schizophrenia? single nucleotide polymorphisms, haplotypes, and gene expression analysis. Biol Psychiatry 2004; 56:169-176.

6. Hattori E, Liu C, Badner JA, Bonner TI, Christian SL, Maheshwari M, et al. Polymorphisms at the G72/G30 gene locus, on 13q33, are associated with bipolar disorder in two independent pedigree series. Am J Hum Genet 2003; 72:1131-1140.

7. Chen YS, Akula N, Detera-Wadleigh SD, Schulze TG, Thomas J, Potash JB, et al. Findings in an independent sample support an association between bipolar affective disorder and the G72/G30 locus on chromosome 13q33. Mol Psychiatry 2004; 9:87-92.

8. Schumacher J, Jamra RA, Freudenberg J, Becker T, Ohlraun S, Otte AC, et al. Examination of G72 and D-amino-acid oxidase as genetic risk factors for schizophrenia and bipolar affective disorder. Mol Psychiatry 2004; 9:203-207.

9. Fallin MD, Lasseter VK, Avramopoulos D, Nicodemus KK, Wolyniec PS, McGrath JA, et al. Bipolar I disorder and schizophrenia: a 440-singlenucleotide polymorphism screen of 64 candidate genes among Ashkenazi Jewish case-parent trios. Am J Hum Genet 2005; 77:918-936.

10. Zou F, Li C, Duan S, Zheng Y, Gu N, Feng G, et al. A family-based study of the association between the G72/G30 genes and schizophrenia in the Chinese population. Schizophr Res 2005; 73:257-261.

11. Detera-Wadleigh SD, McMahon FJ. G72/G30 in schizophrenia and bipolar disorder: review and meta-analysis. Biol Psychiatry 2006; 60:106-114.

12. Korostishevsky M, Kremer I, Kaganovich M, Cholostoy A, Murad I, Muhaheed M, et al. Transmission disequilibrium and haplotype analyses of the G72/G30 locus: suggestive linkage to schizophrenia in Palestinian Arabs living in the North of Israel. Am J Med Genet B Neuropsychiatr Genet 2006; 141:91-95.

13. Addington AM, Gornick M, Sporn AL, Gogtay N, Greenstein D, Lenane $\mathrm{M}$, et al. Polymorphisms in the 13q33.2 gene G72/G30 are associated with childhood-onset schizophrenia and psychosis not otherwise specified. Biol Psychiatry 2004; 55:976-980.

14. Hall D, Gogos JA, Karayiorgou M. The contribution of three strong candidate schizophrenia susceptibility genes in demographically distinct populations. Genes Brain Behav 2004; 3:240-248.

15. Mulle JG, Chowdari KV, Nimgaonkar V, Chakravarti A. No evidence for association to the G72/G30 locus in an independent sample of schizophrenia families. Mol Psychiatry 2005; 10:431-433.

16. Liu YL, Fann CS, Liu CM, Chang CC, Wu JY, Hung SI, et al. No association of G72 and D-amino acid oxidase genes with schizophrenia. Schizophr Res 2006; 12: [Epub ahead of print].

17. Zhang Y, Yu X, Yuan Y, Ling Y, Ruan Y, Si T, et al. Positive association of the human frizzled 3 (FZD3) gene haplotype with schizophrenia in Chinese Han population. Am J Med Genet B Neuropsychiatr Genet 2004; 129:16-19.

18. Shi YY, He L. SHEsis, a powerful software platform for analyses of linkage disequilibrium, haplotype construction, and genetic association at polymorphism loci. Cell Res 2005; 15:97-98.

19. Hong CJ, Hou SJ, Yen FC, Liou YJ, Tsai SJ. Family-based association study between G72/G30 genetic polymorphism and schizophrenia. Neuroreport 2006; 17:1067-1069.

20. Gorwood P, Leboyer M, Jay M, Payan C, Feingold J. Gender and age at onset in schizophrenia: impact of family history. Am J Psychiatry 1995; 152:208-212

21. Childs B, Scriver CR. Age at onset and causes of disease. Perspect Biol Med 1986; 29 (3 Pt 1):437-460.

22. Vourdas A, Pipe R, Corrigall R, Frangou S. Increased developmental deviance and premorbid dysfunction in early onset schizophrenia. Schizophr Res 2003; 62:13-22.

23. DeLisi LE, Friedrich U, Wahlstrom J, Boccio-Smith A, Forsman A, Eklund K, et al. Schizophrenia and sex chromosome anomalies. Schizophr Bull 1994; 20:495-505. 